\title{
Effects of lesions of the nucleus accumbens on lactation and postpartum behavior
}

\author{
MYRA 0. SMITH \\ Colgate University, Hamilton, New York 13346 \\ and \\ ROBERT C. HOLLAND \\ Department of Anatomy, Faculty of Science, Mahidol University, Bangkok, Thailand
}

\begin{abstract}
An attempt was made, using the lesion technique, to confirm results of electric stimulation studies which indicate that the nucleus accumbens (NA) can exercise a facilitatory influence on oxytocin secretion and the milk ejection reflex. Since little is known about the NA, despite its large size, we also investigated other possible functions as well, especially those related to reproduction, lactation, and maternal behavior. Lesions including the dorsomedial NA were followed by heightened emotionality and impaired lactational performance, attributable in some instances to oxytocin deficiency and in others to a possible prolactin insufficiency. Poor lactational performance was accompanied by the absence of maternal behavior. Lesions made in the posterior hypothalamus reversed the latter but not the former, indicating that: (1) inferior maternal behavior was not attributable to hormonal deficiencies underlying poor lactational performance but to the generally excitable state of the animals, and (2) the hormonal deficiencies were direct consequences of the lesion and not secondarily produced by chronic sympathetic activation.
\end{abstract}

Three experiments are reported which deal with the effects of lesions in the nucleus accumbens (NA) on reproduction, lactational performance, and behavior. They were stimulated by the earlier work of Holland and his associates (Aulsebrook \& Holland, 1969a, b; Woods, Holland, \& Powell, 1969) which showed that milk ejection could be triggered selectively in lactating rabbits by electrical stimulation of the medial aspects of this nucleus. This finding was confirmed by Urban, Moss, and Cross (1971) in their investigation of the afferent pathways for oxytocin release. While stimulation of other forebrain structures also produced exclusive release of oxytocin from the neurohypophysis, involvement of the NA aroused our special interest because of the paucity of available information on its functions, despite its large size in the forebrain of mammals.

This research was supported in part by a grant from the Rockefeller Foundation to the Faculty of Science, Mahidol University and by funds provided by the Sloan Foundation to the Psychology Department. Colgate University. The authors wish to thank Chantana Trivitayarat and Boonmee Songthumawat for their technical assistance and Varaporn Thavisin for help in preparation of the manuscript. Myra O. Smith was a Postdoctoral Fellow. National Institute of Child Health and Development. NIH. Mahidol University. and a Postdoctoral Fellow. Sloan Foundation, Colgate University, where she is currently Assistant Professor of Psychology. Send reprint requests to Myra O. Smith, Department of Psychology, Colgate University, Hamilton. New York 13346. Robert C. Holland is a staff member of the Rockefeller Foundation. Visiting Professor of Anatomy at the Faculty of Science.
Its embryological origins and cytoarchitecture suggested to earlier neuroanatomists that it was part of the corpora striatum (Kappers, Huber, \& Crosby, 1936). Yet, no known intercommunicating fibers between the NA and caudate-putamen complex exist (Knook, 1965). On the other hand, connections with the precommissural septal nuclei have been traced (Mizuno, Clemente, \& Sauerland, 1969), and some of its incoming and outgoing fibers have the same origins and destinations as those of the septal nuclei. E. W. Powell (Note 1), employing radioactive leucine injections in the NA, has traced efferent fibers to many areas of the brain of squirrel monkey, including the septum, habenula, and hypothalamus, with heaviest concentration in the lateral hypothalamus. The work of Lorens, Sorensen, and Harvey (1970) and ours together suggest that it may subserve limbic functions, such as regulation of food intake, emotionality, general activity level, and reproductive performance.

\section{EXPERIMENT I}

\section{Method}

Subjects. Virgin albino rats (Fisher strain) from the colony of the anatomy department of Mahidol University were used. Rats weighing 130-150 g were individually housed in wire mesh cages and maintained on an ad-lib schedule of a commercially prepared diet, boiled eggs, and tap water. As they neared $200 \mathrm{~g}$, those with regular estrous cycles were randomly submitted to one of three treatments: lesion in the NA (NA-X), sham surgery (NA-SC), and no surgery (NA-UC).

Surgery. A Grass electrolytic lesion maker (LM3) was used for the bilateral destruction of the NA of 28 rats by passing 
Table 1

Subgrouping of Experimental Rats According to Size of Lesion in Upper Medial One-Third NA

\begin{tabular}{lcr}
\hline Group & \multicolumn{1}{c}{ Lesion Size } & N \\
\hline NA-X & $>50 \%$ bilateral & 9 \\
NA- $X_{2}$ & $>75 \%$ in one NA and $<50 \%$ in other & 5 \\
NA-X & $50 \%-75 \%$ in one NA and $<50 \%$ in other & 6 \\
NA-X & $<50 \%$ bilateral & 4 \\
Total & & 24 \\
\hline
\end{tabular}

a 4.5-mA current between the exposed tip of an insulatedstainless steel cranial cathode and a rectal anode for $30 \mathrm{sec}$. To insure damage along the length of the NA, current was passed at two loci corresponding to König and Klippel's (1963) coordinates A 8.9, L 1.0, H -0.8, and A 9.8, L 0.8, $\mathrm{H}-0.5$. Twenty-four animals survived surgery.

Twelve rats were subjected to the same surgical procedures as the NA group, except that electrodes were inserted and retracted without passage of current. Ten of these NA-SC animals survived. There were no deaths among 12 NA-UC rats.

Determination of lactational performance. Determination of lactational performance consisted of inspecting stomachs of pups, manually expressing milk from teats, and plotting growth rate of pups. The translucency of the abdominal skin of neonatal pups made possible visual detection of milk in the stomach. Two dams that canniablized their young and replacement pups which had not nursed were tested on Day 3 by anesthetizing (to prevent pup devouring) and injecting them with 1 IU oxytocin before placing new substitutes at their teats. The stomachs of pups were examined following $30 \mathrm{~min}$ of suckling, and the net gain in weight was noted.

Histology and brain reconstruction. Rats were overdosed with ether and their brains removed and fixed in Formalin. Reconstruction of the lesion consisted of mounting 50-micron-thick frozen frontal sections of the brain onto slides, staining them with basic fuchsin, and projecting them onto a screen. Determination of the extent and site of destruction proceeded by matching projections with corresponding sections in the atlas of König and Klippel (1963).

To determine whether inadvertent damage to adjacent regions may have produced changes in lactational performance, NA-X rats were segregated into two groups on the basis of whether or not their pups survived the 1 st .week under their care. By comparing damage incurred by both groups, it was possible to eliminate extra-accumbens structures 1 and to narrow the critical area to the dorsomedial one-third of the NA between A $8620 \mu$ and $A 8380 \mu$ of the König and Klippel atlas. For purposes of data analysis, Group NA-X was divided into four subgroups on the basis of the size of the lesion in this crucial area. The criteria for the categories and number of cases falling into each are given in Table 1.

Ratings of emotionality. Because pilot studies had revealed that lesions in the NA frequently produced striking changes in the excitability of rats, systematic observations of behavior were made. Animals were tested by lightly touching them with a thin flexible wire, prodding them gently with the blunt end of a pencil, picking them up, and briefly handling them in a routine manner. Responses were scored as follows: no obvious emotional reaction, 0 ; freezing, 1 ; startle, 2; directed attack, 3 . Experimenters were at no time aware of the identity of rats. They were tested daily for the first 5 days of the postoperative period and every other day thereafter until scores averaged less than 1.0 on 3 consecutive days.

Procedure. Beginning at least a month prior to the experiment, daily records were kept of each rat's vaginal smears and body weight. Any unusual behavior during handling was noted. Only cycling and normally behaving animals were selected for the study.
Upon recovery of preoperative body weight and resumption of regular cycling (usually a month later in the case of NA-X rats), attempts were made to mate them. Unoperated controls were mated 3 to 4 weeks after they had attained $200 \mathrm{~g}$. Males in which fertility had been previously established were placed in their cages on the day of proestrus and removed 2 days later. Vaginal smears were checked for sperm. In the absence of evidence that mating had occurred, a new male rat was placed with the female on the day of proestrus, two cycles later.

At midterm pregnancy, each rat was transferred to a round plastic tub, 4 in. in height, with a floor diameter of 10 in. Tubs were lined with wood shavings, and a wire mesh lid was fitted over each. Two or 3 days before the expected day of parturition, nesting material consisting of paper toweling and excelsior was made available.

At parturition, the size of all litters was adjusted to six pups. Whenever a pup died, it was replaced with another of approximately the same age and weight.

Specific attributes of maternal behavior were noted, including licking and cleaning of pups at birth and, thereafter, ingestion of placenta, cannibalism, time spent nursing, and retrieval. Because a pilot study of normal rats revealed that this particular breed did not consistently construct nests, this index was not utilized.

Other data collected during the course of the experiment included number of actual matings required to effect pregnancy, incidence of resorptions and stillbirths, gestation length, time required to complete parturition, birth weight of pups, and litter size.

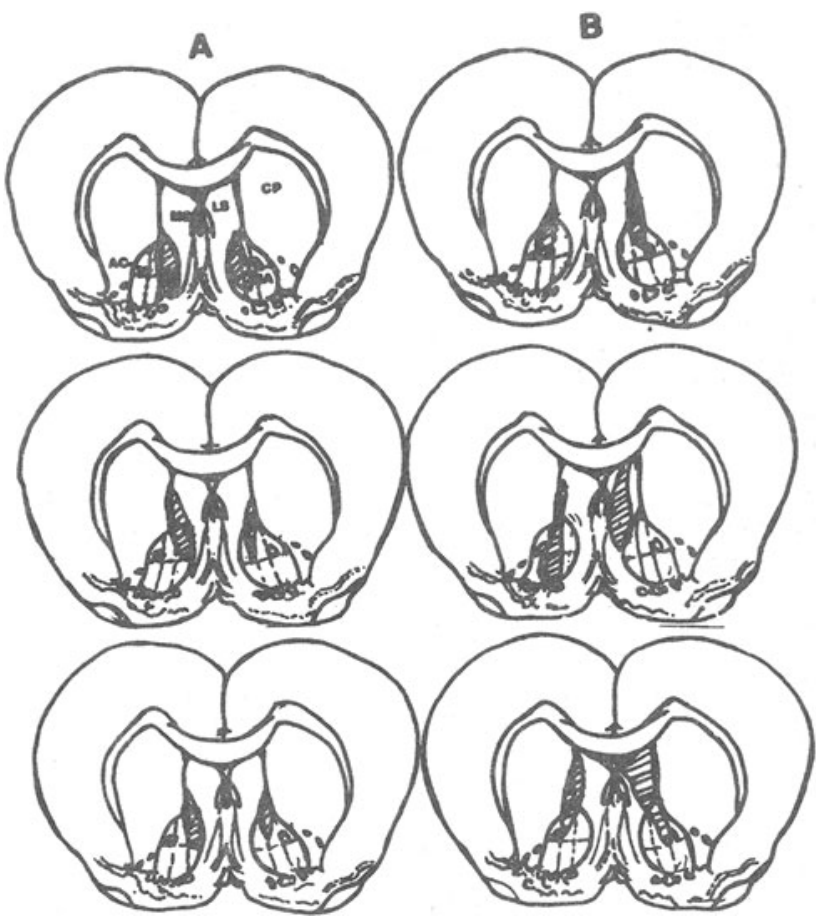

Figure 1. Typical lesions incurred by dams with impaired lactational performance (A) and with unimpaired lactational performance (B). Important landmarks are labeled as follows: AC = anterior commissure; $\mathbf{C P}=$ caudate-putamen; $\mathbf{L S}=$ lateral septum; $M S=$ medial septum; NA = nucleus accumbens. The sections correspond to A $8380 \mu-A 8620 \mu$ of König and Klippel. 
Results

Behavioral changes. Conspicuous behavioral changes suggesting heightened emotionality occurred in 19 out of 24 (79.2\%) NA-X rats. Routine handling elicited postural freezing, jumpiness, and other manifestations of wariness at one extreme, or explosive reactions on the other, such as well-directed attempts to bite, vigorous leaping, and frantic attempts to escape from the cage or the experimenter's grasp. In contrast, only 2 of the $10(20 \%)$ NA-SC dams displayed behavioral changes in the postsurgical period. These were transient and consisted of arrest of ongoing behavior in response to light touch and freezing during handling. The average emotionality rating for subgroups with damage to at least $50 \%$ of the dorsomedial one-third of either or both NA (NA-X $\mathrm{X}_{1}, \mathrm{NA}-\mathrm{X}_{2}$ and $\mathrm{NA}-\mathrm{X}_{3}$ ) was 2.05 , compared to .14 for NA- $\mathrm{X}_{4}$ and NA-UC combined. As shown in Table 2, the differences in incidence of behavioral changes and in average ratings are both significant, $\mathrm{z}=4.22, \mathrm{p}<.0002$ and $\mathrm{t}(32)=7.96$, $\mathrm{p}<.01$, respectively. The aggressive components of behavior tended to subside towards the 14th day of the postlesion period, but hyperactivity, including persistent attempts to escape from cages, continued beyond a fortnight, waning during pregnancy, only to reappear shortly after parturition.

Reproductive performance. In the immediate postoperative period, $18(75 \%)$ of the rats in the NA-X group manifested persistent diestrus that averaged 12 days. Only one of the NA-SC group (10\%) showed constant diestrus, lasting 14 days. The proportion of rats with moderate- to large-sized lesions in this area (NA- $\mathrm{X}_{1}$ $\mathrm{NA}-\mathrm{X}_{2}, \mathrm{NA}-\mathrm{X}_{3}$ ) that experienced a temporary cessation in cycling is significantly greater than that of animals with smaller lesions of this area $\left(\mathrm{NA}-\mathrm{X}_{4}\right)$ or no lesions (SC), $\mathrm{z}=5.27, \mathrm{p}<.0002$. In all cases, normal cycling resumed, enabling mating and impregnation. No significant differences were detected in the number of matings required to effect fertilization, length of gestation, incidence of resorptions and stillbirths, and ease of parturition.

Table 2

Behavioral Changes Produced by Lesion

\begin{tabular}{|c|c|c|c|}
\hline \multirow[b]{2}{*}{ Group } & \multirow[b]{2}{*}{$\mathrm{N}$} & \multicolumn{2}{|c|}{ Hyperemotionality } \\
\hline & & Percentage & Score \\
\hline $\begin{array}{l}\mathrm{NA}-\mathrm{X}_{1} \\
\mathrm{NA}-\mathrm{X}_{2} \\
\mathrm{NA}-\mathrm{X}_{3} \\
\mathrm{NA}-\mathrm{X}_{4} \\
\mathrm{NA}-\mathrm{SC}\end{array}$ & $\begin{array}{r}9 \\
5 \\
6 \\
4 \\
10\end{array}$ & $\begin{array}{r}100.0 \\
100.0 \\
66.7 \\
25.0 \\
10.0\end{array}$ & $\begin{array}{r}2.33 \\
2.40 \\
1.33 \\
.25 \\
.10\end{array}$ \\
\hline $\begin{array}{l}\mathrm{NA}-\mathrm{X}_{1} \text { to NA-X } \\
\mathrm{NA}-\mathrm{X}_{4}+\mathrm{NA}-\mathrm{SC}\end{array}$ & $\begin{array}{l}20 \\
14\end{array}$ & $\begin{array}{l}90.0 \\
14.3\end{array}$ & $\begin{array}{r}2.05 \\
.14\end{array}$ \\
\hline & & $z=4.22 *$ & $t(32)=7.96 * *$ \\
\hline
\end{tabular}

Note-Scores are averages of ratings obtained on Postlesion Day 5.

${ }^{*} p<.0002 \quad * * p<.01$
Table 3

Incidence of Impaired Lactational Performance, Cannibalism

\begin{tabular}{|c|c|c|c|c|}
\hline Group & $\mathrm{N}$ & $\begin{array}{c}\text { ILP } \\
\text { Only } \\
\text { (Percent) }\end{array}$ & $\begin{array}{l}\text { ILP and } \\
\text { Canni- } \\
\text { balism } \\
\text { (Percent) }\end{array}$ & $\begin{array}{c}\text { Total } \\
\text { ILP } \\
\text { (Percent) }\end{array}$ \\
\hline $\begin{array}{l}\text { NA-X } \\
\text { NA-X } \\
\text { NA-X } \\
\text { NA-X } \\
\text { NA-SC } \\
\text { NA-UC }\end{array}$ & $\begin{array}{r}9 \\
5 \\
6 \\
4 \\
10 \\
12\end{array}$ & $\begin{array}{l}55.6 \\
40.0 \\
16.7 \\
25.0 \\
20.0 \\
00.0\end{array}$ & $\begin{array}{l}44.4 \\
40.0 \\
33.3 \\
00.0 \\
00.0 \\
00.0\end{array}$ & $\begin{array}{r}100.0 \\
80.0 \\
50.0 \\
25.0 \\
20.0 \\
00.0\end{array}$ \\
\hline $\begin{array}{l}\mathrm{NA}-\mathrm{X}_{1}+\mathrm{NA}-\mathrm{X}_{2}+\mathrm{NA}-\mathrm{X}_{3} \\
\mathrm{NA}-\mathrm{X}_{4}+\mathrm{NA}-\mathrm{SC}+\mathrm{NA}-\mathrm{UC} \\
\mathrm{z}\end{array}$ & $\begin{array}{l}20 \\
26\end{array}$ & $\begin{array}{l}40.0 \\
11.5 \\
2.24^{*}\end{array}$ & $\begin{array}{l}40.0 \\
00.0 \\
3.64 * *\end{array}$ & $\begin{array}{l}80.0 \\
11.5 \\
4.86 \dagger\end{array}$ \\
\hline
\end{tabular}

Note-ILP: Impaired lactational performance, defined as loss of $50 \%$ or more of litter by Day 20 postpartum.

${ }^{*} p<.03 \quad{ }^{* *} p<.0004 \quad t_{p}<.0002$

The number of pups per litter did not vary significantly from group to group. However, at birth, young delivered by dams with $50 \%$ or greater damage to the upper medial third of the NA tended to weigh less than their counterparts in groups NA-X $\mathrm{X}_{4}, \mathrm{NA}-\mathrm{SC}$, and NA-UC, $\mathrm{t}(42)=2.11, \mathrm{p}<.05$.

Lactational performance. Impaired lactational performance (ILP) was revealed in 17 of the 24 (70.8\%) NA-X dams. Only one of the NA-SC group (10\%) lost all of its young and another lost $50 \%$ of its litter. Of 12 NA-UC dams, none incurred a loss equal to or greater than 50\% of offspring. Moreover, the incidence of ILP appeared to be correlated with the magnitude of the lesion in the upper medial third of the NA. When all groups with $50 \%$ or greater damage to the NA of at least one hemisphere are combined and rats with less than

$50 \%$ bilateral destruction are considered together with NA-SC and NA-UC groups, the difference in incidence of ILP is significant, as shown in Table $3, z=4.86$, $\mathrm{p}<.0002$.

Cannibalism. Cannibalism was prevalent in NA-X rats. In all cases, it was associated with ILP. Of rats in subgroups $\mathrm{NA}-\mathrm{X}_{1}, \mathrm{NA}-\mathrm{X}_{2}$ and $\mathrm{NA}-\mathrm{X}_{3}$, eight $(40 \%)$ devoured their pups within the first 3 days of parturition. None in NA- $\mathrm{X}_{4}$ or the two control groups cannibalized their young. Table 3 shows this difference to be significant, $z=3.64, p<.0004$.

From the outset, cannibalistic dams failed to display maternal interest. They tolerated only for short periods suckling initiated by young or at the coaxing of experimenters. When not attacking pups, they were occupied digging vigorously in the sawdust, biting cage lids, and trying to escape from their cages. They exhibited indifference to straying young or to pups that had become detached from teats as they were being dragged.

Because these dams permitted only sporadic suckling, growth rate could not be used as an index of ILP. We depended, therefore, on detection of milk in stomachs 
of pups immediately following a nursing period of $5 \mathrm{~min}$ or longer and on attempts to manually milk the dams. These measures revealed milk secretion in only one mother, whose pups were still gaining weight, although at a subnormal rate, when she devoured them on Day 3. Two dams that ate their pups and replacements which had not nursed were anesthetized and injected with oxytocin on Day 3. The stomachs of healthy but hungry 5-day-old replacements that suckled at their teats were empty at the end of $30 \mathrm{~min}$. Experimenters could not express milk from the mammary glands, which appeared, under scrutiny, to be underdeveloped.

Maternal behavior in noncannibalistic dams. Poor lactational performance not associated with cannibalism was observed in nine NA-X dams. Six of these lost their litters within the first 5 postnatal days, and three more lost at least half before weaning on Day 20 . The latter includes one dam whose entire litter had starved to death by Day 4 but which subsequently succeeded in rearing three out of six replacement pups.

Traces of milk were deteotable in stomachs of many pups nursed by noncannibalistic NA-X dams during the first 2 days of life, but in amounts that were clearly less than in pups surviving to weaning. On Days 3 and 4, stomachs of malnourished pups appeared empty even after protracted periods of suckling.

Although all noncannibalistic mothers were seen to initiate nursing of their young and replacements within the first 3 or 4 days postpartum, interest in pups waned rapidly. In part, this could be attributed to the weakened condition of their starving young, which prevented effective suckling. However, replacing these with eager, healthy pups did not reinstate interest in nursing; rather, they spent much of the time trying to escape from replacements, dragging and scattering them throughout the cage. Their behavior from the 4th day on, except for pup devouring, was indistinguishable from that of cannibalistic dams.

\section{DISCUSSION}

It is clear that destruction of the upper medial $1 / 3$ of the NA affected lactational performance and maternal behavior. The question was raised whether the lesion disrupted hormonal secretions critical to either or both functions or whether it produced these effects only secondarily, through heightened activation of the sympathetic system.

Oxytocin and the milk ejection it produces are necessary not only for continued milk production but for the prevention of painful mammary engorgement. While it is probably not the reason that lactating animals seek to nurse their young in the first place (Moltz, Geller, \& Levin, 1967), relief from the discomfort that it produces can serve as an important reinforcing agent for the continuation of nursing. Persisting engorgement, despite attempts to nurse, will deprive the animal of a tangible incentive to engage in this behavior and thus lead to its extinction.

On the other hand, it is known that sympathetic activation has inhibitory effects upon both the release of oxytocin (Cross, 1955, 1961, 1964) and of prolactin (Coppola, 1971), a hormone known to be essential to milk secretion (Cowie \& Tindal, 1971; Denamur, 1971) and possibly to the postparturient induction of maternal behavior in rat (Moltz, Lubin, Leon, \& Numan, 1970; Rosenblatt, 1967; Rosenblatt \& Lehrman, 1963; Zarrow, Gandelman, \& Denenberg, 1971).

In the experiment next to be reported, an attempt was made to test the possibility that oxytocin deficiency, directly or indirectly attributable to the NA lesion, lay at the basis of the lactational impairment. While the administration of exogneous oxytocin to the two cannibalistic dams in the present experiment failed to precipitate the flow of milk, it is possible that the timing of injection was faulty. Engorged glands due to failure in milk ejection during the first 3 days may have exerted negative feedback upon milk synthesis or secretion, with the result that oxytocin introduced on Day 3 may have been acting upon regressing mammary tissue.

\section{EXPERIMENT II}

\section{Method}

Subjects. Subjects were a new group of 15 NA-X, lactation-deficient dams which weighed an average of $275 \mathrm{~g}$ and had recently successfully completed their first gestation.

Exogenous oxytocin administration. Rats were randomly assigned to four groups, each receiving two daily doses of 1 IU oxytocin over a 3-day period. The postpartum day on which treatment was initiated varied with the groups as follows: Group 1, Day 1; Group 2, Day 2; Group 3, Day 3; Group 4, Day 4. Each group had four dams, except for Group 3, which had three.

Tests for milk ejection. The efficacy of oxytocin therapy was tested in two ways. Six healthy pups that previously had been separated from normally lactating mothers for $8 \mathrm{~h}$ were placed at the teats of lightly anesthetized dams for $30 \mathrm{~min}$ following the morning oxytocin injection. The change in weight for each litter that occurred over the nursing period was noted. At the conclusion of this period, attempts were made to manually express milk from the teats.

\section{Results}

Of the 15 rats subjected to the foregoing tests, only two noncannibalistic dams responded to oxytocin treatment. These two had been regularly nursing their young, albeit unsuccessfully, at the time therapy was instituted on Day 2. All other dams, including six cannibalistic ones that began treatment on Days 1 and 2 failed to yield milk. Subsequently, three cannibalistic and three of four noncannibalistic dams that did not respond to treatment initiated on Day 4 were remated. The former three again proved to be without milk and to be pup-devouring. The latter three were all capable of rearing viable litters without the assistance of exogenous hormones. 


\section{Discussion}

The success of oxytocin injections in treating ILP if instituted before Day 2 in noncannibalistic but not in cannibalistic NA-X dams suggests that disruption of the milk ejection reflex had occurred in the former while in the latter, milk secretion alone, or in combination with oxytocin deficiency, had been affected.

In the rat, prolactin is known to be the single most important hormone for the initiation and maintenance of milk secretion (Cowie \& Tindal, 1971; Denamur, 1971). It appears, therefore, to be the hormone that was most likely blocked by the NA-X in rats unresponsive to oxytocin administration. Unfortunately, we could not test this because of the unavailability to us of prolactin. However, there is indirect evidence in support of this possibility. Averill (1965) and Averill and Purves (1963) reported that lesions in the lateral hypothalamus (LH) impaired lactational performance in rats. Prolactin, but not oxytocin, was able partially to reverse this condition. Their data are made relevant to our observations by the finding of Powell (Note 1) that the NA has abundant efferent connections with the LH.

A secondarily developing prolactin deficiency may account for the ineffectiveness of oxytocin administered after Day 2 to noncannibalistic dams. The disruption of the milk ejection reflex can conceivably precipitate a recession of conditions stimulating the release of prolactin from the pituitary (see, e.g., Nicoll, 1971; Sgouris \& Meites, 1953).

The question remains whether the prolactin deficiency proposed as an explanation for ILP also underlies the inferior maternal behavior of cannibalistic and the waning of maternal interest in noncannibalistic dams. Or is their poor showing explainable merely by the incompatibility of maternal behavior with the hyperemotional state evident from the very beginning of the postlesion period? If the latter interpretation is valid, then reducing emotionality should permit emergence of positive pup-oriented behavior. The next experiment was conducted to verify this possibility.

\section{EXPERIMENT III}

\section{Method}

Subjects. Subjects were 12 nonlactating NA-X, 6 lactating NA-SC, and 6 lactating NA-UC dams from the Hooded Rat Colony of the Psychology Department at Colgate University. None of the NA-X rats responded to oxytocin treatment or displayed maternal behavior.

Procedure. On the 2nd day postpartum, bilateral electrolytic lesions were made in the posterior hypothalamus (PH) of eight NA-X, four NA-SC, and four NA-UC dams in an effort to reduce sympathetic arousal. Lesions were made at a site corresponding to Pellegrino and Cushman's stereotaxic coordinates, A 4.6, L 0.5, H -2.6 (Pellegrino \& Cushman, 1967). The decision to enter the hypothalamus was made after adrenal medullectomy in three NA-X rats failed to produce noticeable diminution of aggressive behavior. A subsequent pilot study confirmed our expectation, based on the research of Hess (1954) and Gellhorn $(1957,1964)$, that a lesion in this area would reduce emotionality. Six of the NA-X $+\mathrm{PH}-\mathrm{X}$ dams and three each of $\mathrm{NA}-\mathrm{SC}+\mathrm{PH}-\mathrm{X}$ and NA-UC $+\mathrm{PH}-\mathrm{X}$ survived the lesion in the PH.
When they had recovered from anesthesia, six healthy pups were introduced into the cages of each dam. Their responses to the pups and results of nursing attempts were noted. Milk-deficient dams were administered 1 IU oxytocin at 10:00 a.m. and 2:00 p.m. for á period of 3 days.

\section{Results}

Lesions in the PH transformed NA-X dams into gentle animals that approached pups in a curious, nonaggressive way. They sniffed, prodded with their noses, and licked anal regions of pups newly introduced into their cages. Moreover, dams were receptive for the first time to attempts of young to nurse. In more than $75 \%$ of the 12 half-hourly checks made daily, these dams were seen to be crouched over their suckling foster pups.

The passive acquiescence to suckling apparent on the first 2 postoperative days was supplanted by active maternal solicitude in the form of retrieval and grooming of young. Strips of paper partially inserted through the bars of cage lids were pulled in, shredded, and formed into a loose ball-shaped nest which was drawn over the pups. In contrast, strips available to NA-X rats with no lesion in the $\mathrm{PH}$ were chewed, trampled on, or ignored.

In three of the NA-X + PH-X rats; milk secretion was evident on the 1st postoperative day following oxytocin injection. This was not observed again on subsequent days, and it is concluded that the small amount of milk released resulted from the artififactual secretion of prolactin that sometimes accompanies disturbance of basal portions of the brain. The nipples of all the $\mathrm{NA}-\mathrm{X}+\mathrm{PH}-\mathrm{X}$ rats were stretched, reddish, and, in some cases, badly mangled, indicating persistent suckling by hungry, thwarted pups. In contrast, teats of $\mathrm{NA}-\mathrm{X}+\mathrm{PH}-\mathrm{SC}$ and NA-X + PH-UC were concealed in the fur and, when exposed for examination, appeared pale.

The lesion in the $\mathrm{PH}$ did not affect lactational performance or behavior of NA-SC + PH-X or $\mathrm{NA}-\mathrm{UC}+\mathrm{PH}-\mathrm{X}$ dams. The somnolence that sometimes follows lesions in the PH (Ranson, 1939) was not evident. Growth rate of pups continued to be in line with that found typical for pups in the colony as a whole.

\section{Discussion}

Thus, it is evident that the deficiency of hormonal secretions necessary to support lactation is not related to the absence of maternal behavior in the NA-X rats. The $\mathrm{PH}-\mathrm{X}$ effectively separated these two variables, showing that the failure of maternal behavior to develop was a manifestation of a more general disorganization of behavior due to NA-X-produced sympathetic activation. The results are consistent with those of Rosenblatt (1967) which demonstrated that maternal behavior in rats, while facilitated by parturition-related hormonal changes, can occur independently of them.

This study also showed that the lactational deficiency is not secondary to lesion-induced sympathetic arousal; rather, it suggests that the NA in intact, postparturient 
animals exerts a significant facilitatory influence upon the neural mechanism mediating prolactin and/or oxytocin release.

Taken together, the three experiments show that the NA is not involved in the hormonal secretions essential to reproductive processes in the female rat. They do, however, point to an important facilitatory influence of the NA upon the mechanism for oxytocin release. They also suggest involvement of the NA in the secretion of a lactogenic hormone, which we have good reasons to believe is prolactin. The proposed deficiencies in these hormones are direct effects of NA-X and not secondary to the sympathetic activation which also was precipitated. However, the absence or transient nature of maternal behavior which characterized rats with ILP is attributable to the sympathetic activation and thus cannot be said to result from the lesion itself.

\section{REFERENCE NOTE}

1., Powell, E. W. Personal communication, April 1973.

\section{REFERENCES}

Aulsebroox, L. H., \& Holland, R. C. Central regulation of oxytocin release with and without vasopressin release. American Journal of Physiology, 1969, 216, 818-829. (a)

Aulsebrook, L. H. \& HollaNd, R. C. Central inhibition of oxytocin release. American Journal of Physiology, 1969, 216, 830-842. (b)

AVERILL, R. L. W. Restoration of lactation in rats with hypothalamic lesions which inhibit lactation. Journal of Endocrinology, 1965, 26, 463-477.

Averill, R. L. W., \& Purves, H. D. Differential effects of permanent hypothalamic lesions which inhibit lactation. Journal of Endocrinology, 1963, 31, 191-196.

Coppola, J. A. Brain catecholamines and gonadotropin secretion. In L. Martini \& W. F. Ganong (Eds.), Frontiers in neuroendocrinology. New York: Oxford University Press, 1971.

Cowie, A. T., \& Tindal, J. S. The physiology of lactation. Baltimore: Williams \& Wilkins, 1971.

Cross, B. A. The hypothalamus and mechanism of sympatheticoadrenal inhibition of milk ejection. Journal of Endocrinology, 1955, 12, 15-28.

Cross, B. A. Neural control of lactation. In S. K. Kon \& A. T. Cowie (Eds.), Milk: The mammary gland and its secretions (Vol. 1). New York-London: Academic Press, 1961.

Cross, B. A. The hypothalamus in mammalian homeostasis. S. E. B. Symposia: Homeostasis and feedback mechanisms, 1964, 18, 157-194.

Denamur, R. Hormonal control of lactogenesis. Journal of Dairy Research, 1971, 38, 237-264.

Gellhorn, E. Autonomic imbalance and the hypothalamus. Minneapolis: University of Minnesota Press, 1957.

GellhorN, E. Motion and emotion: The role of proprio- ception in the physiology and pathology of the emotions. Psychological Review, 1964, 71, 457-472.

Hess, W. R. Diencephalon: Autonomic and extrapyramidal functions. New York: Grune and Stratton, 1954.

Kappers, C. V. A., Huber, G. C., \& Crosby, E. C. The comparative anatomy of the nervous system of vertebrates including man (Vol. 2). New York: MacMillan, 1936.

KNoox, M. L. The fibre-connections of the forebrain. Essen, The Netherlands: Van Gorcum, 1965.

KönIG, J. F. R., \& KLIPPEL, R. A. The rat brain: A stereotaxic atlas of the forebrain and lower parts of the brain stem. Baltimore: Williams and Wilkins, 1963.

Lorens, S. A., Sorensen, J. P., \& Harvey, J. A. Lesions in the nuclei accumbens septi of the rat: Behavioral and neurochemical effects. Journal of Comparative and Physiological Psychology, 1970, 73, 284-290.

Mizuno, N., Clemente, C. D., \& Sauerland, E. K. Fiber projections from the rostral basal forebrain in the cat. Experimental Neurology, 1969, 25, 220-237.

Moltz, H., Geller, D., \& LeViN, R. Maternal behavior in the totally mammectomized rat. Journal of Comparative and Physiological Psychology, 1967, 64, 225-229.

Moltz, H., Lubin, M., Leon, M., \& Numan, M. Hormonal induction of maternal behavior in the ovariectomized nulliparous rat. Physiology and Behavior, 1970, 5, 1373-1377.

Nicoll, C. S. Aspects of the neural control of prolactin secretion. In L. Martini \& W. Ganong (Eds.), Frontiers in neuroendocrinology. New York: Oxford University Press, 1971.

Pellegrino, L. J., \& Cushman, A. J. A stereotaxic atlas of the rat brain. New York: Appleton-Century-Crofts, 1967.

RANson, S. W. Somnolence caused by hypothalamic lesions in the monkey. Archives of Neurology and Psychiatry, 1939, 41, 1-23.

Rosenblatt, J. S. Nonhormonal basis of maternal behavior in the rat. Science, 1967, 156, 1512-1514.

Rosenblat,, J. S., \& Lehrman, D. S. Maternal behavior of the laboratory rat. In $H$. L. Rheingold (Ed.), Maternal behavior in mammals. New York: Wiley, 1963.

Sgouris, J. T., \& Merres, J. Differential inactivation of prolactin by mammary tissue from pregnant and parturient rats. American Journal of Physiology, 1953, 175, 319-321.

Urban, I., Moss, R. L., \& Cross, B. A. Problems in electrical stimulation of afferent pathways for oxytocin release. Journal of Endocrinology, 1971, 51, 347-358.

Woods, W. H., Holland, R. C., \& Powell, E. W. Connections of cerebral structures functioning in neurohypophysial hormone release. Brain Research, 1969, 12, 26-46.

Zarrow, M. X., Gandelman, R., \& Denenberg, V. H. Prolactin: Is it an essential hormone for maternal behavior in the mammal? Hormones and Behavior, 1971, 2, 343-354.

\section{NOTE}

1. Lesions were large and in many cases invaded peripheral regions of the septal nuclei, caudate nucleus, diagonal band of Broca, the corpus callosum, and cerebral cortex. Lesions were uniform in neither shape, size, nor placement. This was due, in part, to frequent fluctuations in the city (Bangkok) line voltage in the course of each day.

(Received for publication February 1, 1975; revision accepted April 29, 1975.) 